\title{
Hormones and Reproductive Cycles in Snakes
}

\author{
Emily N. Taylor and Dale F. DeNardo
}

\begin{abstract}
SUMMARY
The study of the hormonal regulation of reproduction in snakes is in its infancy. Studies have disproportionately examined temperate zone viperid and colubrid snakes, especially the redsided garter snake (Thamnophis sirtalis parietalis). Indeed, extensive observational and experimental studies on $T$. s. parietalis form the basis for our understanding of the hormonal regulation of reproduction in snakes. This review focuses on seasonal hormone concentrations in snakes in relation to events in the reproductive cycle; the limited data available on hypothalamic hormones, gonadotropins (GTHs), hormone receptors, and binding globulins; the neuroendocrinology of reproduction; and the environmental, social, physiological, and embryonic aspects of hormonal regulation of reproduction in snakes. The review ends with suggestions for future research, including studies of a more diverse ecological and taxonomic representation of snakes, experimental studies on the effects of hormones on reproductive tissues and behaviors, and further research into the neuroendocrinology of reproduction in this highly diverse group of animals.
\end{abstract}

\section{INTRODUCTION}

Despite there having been a fair number of studies conducted on snake reproduction, these studies have predominantly been conducted on a relatively small number of temperate species. Further, up until the past few decades, studies of snake reproduction have been mostly anatomical, being limited to the histology of the male reproductive organs to quantify the timing of spermatogenesis and the examination of female reproductive tracts for evidence of vitellogenesis. This review focuses on current knowledge of the hormonal regulation of reproduction in snakes. Because so many studies have been published on the hormonal regulation of various aspects of reproduction in snakes, especially the red-sided garter snake (Thamnophis sirtalis parietalis), we attempt to provide a broad overview of the effects of hormones on reproduction in snakes, focusing on seminal studies and referring to review articles when possible. First, we describe what is known about the relationship between sex steroids and reproduction in snakes. In this section, we discuss $T$. s. parietalis separately from all other snake species. Although such a distinction is not phylogenetically justified, it enables us to provide a thorough presentation of the most well-studied species without biasing the review of reproductive endocrinology of snakes in general with data from a single species. We then discuss the limited literature on hypothalamic hormones, gonadotropins (GTHs), hormone receptors, binding globulins, and neuroendocrinology for all snakes. We follow this with a discussion of environmental, behavioral, and non-reproductive physiological influences on hormones and reproduction in snakes, ending with suggestions for future research.

\section{HORMONES AND REPRODUCTIVE CYCLES IN SNAKES}

Saint Girons (1982) reviewed the reproductive cycles of male snakes in relation to female cycles and climate. In doing so, Saint Girons described four patterns of male reproduction. First, the postnuptial (dissociated) or estival type, which occurs in many temperate and subtropical species, is a pattern in which males undergo spermatogenesis during the summer, sperm are stored over the winter (in the vasa deferentia and sometimes also in female oviducts if fall mating occurs), and the principal mating season occurs in spring. This postnuptial pattern of spermatogenesis is predominant among temperate colubrids and crotalines. Second is the prenuptial (associated) or vernal type, which typically occurs in warm climates. In this type, spermatogenesis begins in the fall and is completed by the following spring or early summer, at which time mating occurs. Third is the 'mixed type,' which is characterized by spermatogenesis beginning in spring and being completed one year later; there can be one (spring) or two (spring and fall) mating seasons. As with 
the postnuptial pattern, the mixed type typically occurs in temperate and subtropical species. Finally, the continuous type describes species in environments where there is little seasonal variation in temperature (e.g., most tropical areas). As the name implies, species that express continuous male reproduction exhibit spermatogenesis and mating behavior throughout the year. Although distinct in definition, these four types of male reproduction in snakes should be viewed as noteworthy points along a cline from distinctly seasonal (displaying estival spermatogenesis) to aseasonal (displaying continuous spermatogenesis), as exceptions certainly exist (Saint Girons, 1982).

Reproductive cycles in female snakes are less variable than in males. Females typically produce, at most, a single clutch or litter per year. Many species exhibit less-thanannual reproduction, in that not all adult females reproduce each year (Duvall, Arnold, \& Schuett, 1992). In most species studied, the timing of reproductive events is such that neonates are born or hatched when resources are abundant and climatic conditions are favorable. Typically, ovulation occurs in late spring or early summer, and hatching or parturition occurs in summer or early fall (Saint Girons, 1982). Of course, exceptions exist, especially in tropical species in which reproduction may occur at any time of year, and there may be multiple clutches per year. In fact, aseasonal reproduction may well be the dominant reproductive pattern in female snakes, considering the higher diversity of snakes in the tropics (Stevens, 1989; Reed, 2003), but these species are mostly unstudied.

Whereas the timing of reproduction is most frequently assessed according to the traditional seasons (spring, summer, fall, and winter in the northern or southern hemispheres), other critical factors including annual weather patterns, altitude, phylogeny, foraging mode, body size, and body condition also regulate the timing of reproduction (Dunham, Miles, \& Reznick, 1988; Vitt, 1992). To more fully understand reproductive timing, it is essential to understand reproductive physiology, especially the relationships between hormones and events in reproduction (e.g., mating, spermatogenesis, vitellogenesis, gestation, parturition). Such studies have been conducted relatively recently in snakes. Snakes are notoriously secretive animals, but advances in techniques for following individual snakes in the wild (e.g., radiotelemetry) as well as in methods of quantifying hormones (e.g., radioimmunoassay) in the $1970 \mathrm{~s}$ and $1980 \mathrm{~s}$ allowed researchers to begin examining the hormonal regulation of reproduction in snakes. Some of the earliest studies examined snake GTHs and sex steroid hormones, in general confirming that the structure and function of these hormones in snakes are similar to those of their better-studied mammalian counterparts. In particular, $T$. s. parietalis emerged as a model organism for studies of hormonal regulation of reproduction in snakes (Krohmer, 2004), largely because a population in Manitoba, Canada that dens communally by the thousands provided accessibility to large numbers of snakes for both field and laboratory experiments. Most of our knowledge of advanced topics in this field comes from studies of $T . s$. parietalis. These studies have provided extremely valuable insights into the hormonal regulation of reproduction in snakes, due to the ease of sampling multiple individuals as well as their ready display of mating behaviors in captivity. However, the extremely high latitude and the unique mating behavior of this population call into question the applicability of these results to snakes in general. Recent studies by several laboratories have provided data on the hormonal regulation of reproduction in other snake species. These comparative data have proven quite valuable, but the universality of existing knowledge on snake reproductive physiology must remain uncertain as these additional studies still disproportionately represent temperate species, especially viperids.

Crews (1984) reviewed studies examining the temporal association of mating and gonadal activity (defined as gametogenesis and/or secretion of sex steroid hormones) in seasonally breeding organisms. He differentiated between species showing associated and dissociated reproductive tactics (Figure 13.1). Species showing associated reproductive tactics exhibit mating that is coincident with elevated gonadal activity, whereas species showing the dissociated reproductive pattern mate when gonadal activity is basal. These terms can be applied to both males and females; sometimes both sexes show the same tactic, while at other times the sexes differ. Considering the patterns of spermatogenesis reviewed by Saint Girons (1982), the estival or postnuptial pattern most closely resembles the dissociated tactic, and the vernal or prenuptial pattern most closely resembles the associated tactic. Although the dissociated and associated patterns clearly represent extremes, and many species show tactics intermediate between these extremes, the distinction provides a useful framework for examining the dependence of mating behaviors upon gonadal hormones. In this section, we describe how these paradigms have been applied to snakes. With notable exceptions, it appears that the majority of male snakes of those few species examined indeed exhibit mating behaviors when plasma testosterone (T) concentrations are high. Females of these same species, on the other hand, will often mate at times when circulating sex steroid concentrations are basal.

\subsection{Steroids and Reproduction in Snakes other than Thamnophis sirtalis parietalis}

Studies of plasma steroid hormone concentrations in freeranging snakes (other than $T$. s. parietalis) have mostly 


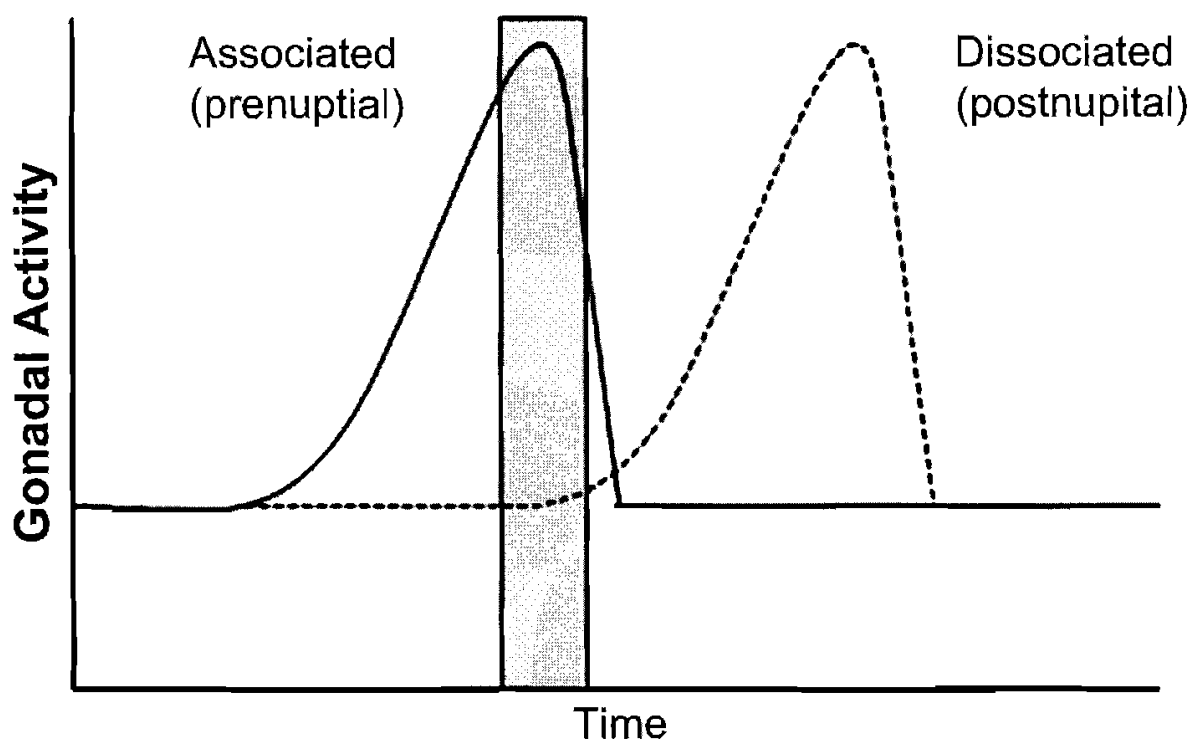

Figure 13.1 Associated and dissociated reproductive patterns. The shaded bar represents mating activity. Gonadal activity is usually defined as sex steroid hormone secretion, although it can also refer to production of gametes. Modified from Crews (1984). been conducted on vipers, with several studies on colubrids and other families. These studies typically examined seasonal variation in hormone concentrations in relation to reproductive events, including mating, spermatogenesis, vitellogenesis, and gestation. In many viperid species, reproduction is seasonal, but not all females reproduce in a given year. Thus, it is possible to collect blood samples for hormone quantification simultaneously from nonreproductive and reproductive females in a single population. This is advantageous for studying the relationship between hormones and reproduction because differences in hormone concentrations between these groups can more likely be attributed to reproduction (although correlated variables such as body condition may contribute to such differences). In addition, intra-specific and inter-specific variation in the association between mating and follicular activity allows hormonal changes responsible for mating behaviors to be at least partially uncoupled from those responsible for physiological events.

\subsubsection{Females}

In general, studies of the relationship between steroid hormones and reproduction in female snakes show that plasma $17 \beta$-estradiol $\left(\mathrm{E}_{2}\right)$ (and in some studies, $\mathrm{T}$ ) is elevated during vitellogenesis, reflecting its role in stimulating production of vitellogenin by the liver (Ho, KleisSan Francisco, McPherson, Heiserman, \& Callard, 1982). Plasma progesterone $\left(\mathrm{P}_{4}\right)$ is often elevated during gestation in viviparous snakes, reflecting its role in the maintenance of pregnancy (Mead, Eroschenko, \& Highfill, 1981; reviewed in Custodia-Lora \& Callard, 2002). Taylor, DeNardo, and Jennings (2004) described the following patterns in female western diamondback rattlesnakes
(Crotalus atrox). Plasma concentrations of $\mathrm{E}_{2}, \mathrm{~T}$, and $\mathrm{P}_{4}$ were low throughout the year if females did not reproduce in that year. If females did reproduce, $\mathrm{E}_{2}$ was elevated from March through June, and especially in April and May. This timing coincides with vitellogenesis in C. atrox (Taylor \& DeNardo, 2005) and in many other temperate species. Testosterone concentrations are low throughout the year in reproductive females, with a slight elevation in spring that may be due to the production of $E_{2}$ ( $T$ being a precursor to $\mathrm{E}_{2}$ in steroid biosynthesis). Increased plasma $\mathrm{T}$ during vitellogenesis was observed in the Chinese cobra (Naja naja) (Bona-Gallo, Licht, MacKenzie, \& Lofts, 1980) and three species of marine snake (Acrochordus granulatus, Cerberus rhynchops, Laticauda colubrina) (Gorman, Licht, \& McCollum, 1981). Saint Girons, Bradshaw, and Bradshaw (1993) found that females displaying mating behaviors had significantly higher plasma dihydrotestosterone (DHT) concentrations, but not T concentrations, than females that were not displaying mating behaviors; however, sample size was very low in this analysis. In C. atrox, $\mathrm{P}_{4}$ is elevated in reproductive females in May through August, and peaks in June/July, corresponding with the gestation period (Taylor \& DeNardo, 2005). In the oviparous $N$. naja, $\mathrm{P}_{4}$ concentrations similarly are elevated from ovulation until oviposition (Bona-Gallo et al., 1980). In C. atrox, plasma corticosterone (CORT) concentrations are more variable annually than the other steroid hormones, but increase dramatically in reproductive females in July and August, during late gestation. Plasma CORT, along with $\mathrm{P}_{4}$, concentrations return to baseline by September (after parturition) in reproductive females (Taylor et al., 2004).

Plasma $\mathrm{E}_{2}$ and $\mathrm{P}_{4}$ concentrations also have been quantified in viperids from Europe, Asia, and South America. 
Female aspic vipers (Vipera aspis) in France have the same seasonal mating patterns as C. atrox (spring vitellogenesis and late summer parturition), and also show elevated $E_{2}$ during spring (Saint Girons et al., 1993). Interestingly, reports of plasma $\mathrm{P}_{4}$ concentrations in reproductive $V$. aspis are inconsistent. Saint Girons et al. (1993) concluded that plasma $\mathrm{P}_{4}$ is highly variable among snakes, with no clear difference between reproductive and non-reproductive females. However, in other studies, plasma $\mathrm{P}_{4}$ concentrations of reproductive female $V$. aspis are elevated in May through August (gestation), decrease in September (after parturition), and rise again during winter (Naulleau \& Fleury, 1990; Bonnet, Naulleau, Bradshaw, \& Shine, 2001). Bonnet et al. (2001) hypothesized that the winter increase in $\mathrm{P}_{4}$, which is especially marked in post-reproductive snakes, may act to block vitellogenesis in emaciated snakes, as $\mathrm{P}_{4}$ may inhibit hepatic synthesis of vitellogenin (Callard et al., 1992; Callard, Giannoukos, CharnockJones, Benson, \& Paolucci, 1994). In Chinese green tree vipers, Viridovipera (Trimeresurus) stejnegeri, $\mathrm{E}_{2}$ concentrations are slightly elevated during vitellogenesis and $\mathbf{P}_{4}$ concentrations are dramatically elevated during gestation (Tsai \& Tu, 2001). Almeida-Santos et al. (2004) found similar relationships between sex steroid concentrations and reproductive states in female Neotropical rattlesnakes (Crotalus durissus terrificus) in southeastern Brazil. In this species $\mathrm{E}_{2}$ peaks during vitellogenesis (winter) and $\mathrm{P}_{4}$ is high during gestation (late winter, spring, and summer), whereas both hormones are low throughout the year in nonreproductive females.

\subsubsection{Males}

As with females, the intra-specific and inter-specific variation in the number of mating periods per year and timing of the mating periods relative to gonadal activity among temperate male snakes provides a potential opportunity to uncouple the relationship between $\mathrm{T}$ and breeding behavior from that of $\mathrm{T}$ and other physiological events, including spermatogenesis. Several studies have shown that $\mathrm{T}$ is elevated during the breeding season(s), providing a strong indication that $\mathrm{T}$ stimulates reproductive behaviors in male viperids.

In viperid species with a single annual breeding season, plasma $\mathrm{T}$ concentrations are high when spermatogenesis and breeding behaviors are occurring. In the cottonmouth (Agkistrodon piscivorus), $\mathrm{T}$ peaks in late summer, at the same time that males show spermiogenic activity, hypertrophy of the sexual segment of the kidney, and breeding behavior (Johnson, Jacob, \& Torrance, 1982; Zaidan, Kreider, \& Beaupre, 2003; Graham, Earley, Hoss, Schuett, \& Grober, 2008). Similarly, the black-tailed rattlesnake (Crotalus molossus) has a single mating season (late summer) and shows a single annual peak in
T concentrations during this time (Schuett et al., 2005). The Chinese cobra ( $N$. naja) and European adder (Vipera berus) show a similarly coordinated single peak in $\mathrm{T}$ at the same time as spermiogenesis and mating, although these occur in the spring rather than late summer (Lofts, Phillips, \& Tam, 1966; Bona-Gallo et al., 1980; Naulleau \& Fleury, 1984).

Many snake species show two annual mating seasons, usually in spring and fall (separated by summer and winter periods of reproductive inactivity). Water snakes (Nerodia sipedon); rough greensnakes (Opheodrys aestivus); C. atrox; Mojave rattlesnakes (Crotalus scutulatus); and $V$. aspis breed in both spring and fall, and males show elevated $\mathrm{T}$ in both of these seasons (Aldridge, Greenhaw, \& Plummer, 1990; Weil \& Aldridge, 1981; Naulleau, Fleury, \& Boissin, 1987; Saint Girons et al., 1993; Schuett et al., 2002; Taylor et al., 2004; Schuett et al., 2005). C. atrox and C. scutulatus show bimodal peaks in circulating DHT at the same time as the peaks in T (Schuett et al., 2002; 2005), although DHT concentrations are much lower than $\mathrm{T}$ concentrations. In a laboratory study, $\mathrm{T}$ concentrations of copperheads (Agkistrodon contortrix) peak in spring and late summer, corresponding to their breeding seasons (Schuett, Harlow, Rose, Van Kirk, \& Murdoch, 1997). These species show the estival or postnuptial pattern of spermatogenesis: $\mathrm{T}$ concentrations are high during spermatogenesis and mating in the late summer and fall, but are also high during the spring when mating is occurring in the absence of spermatogenesis. Testosterone concentrations are lowest in summer, when breeding activity does not occur. In the Sonoran Desert, $C$. atrox sampled while basking during the winter, when the species is mostly inactive, exhibit $T$ concentrations intermediate between those of summer (lowest) and of the spring and fall breeding seasons (Schuett et al., 2006). The reason for elevated $\mathrm{T}$ concentrations in winter is unknown, but it is possible that basking behavior during mild winter days prepares the snakes for the abrupt onset of the spring mating season.

Interestingly, absolute plasma steroid hormone concentrations of many viperids appear to be much higher than those of most other snakes and other vertebrates. For example, peak $\mathrm{T}$ concentrations in $A$. contortix and rattlesnakes are in the region of $100 \mathrm{ng} / \mathrm{mL}$ (Schuett et al., 1997a; 2002; Taylor et al., 2004; Schuett et al., 2005), which is $1-3$ orders of magnitude higher than concentrations observed in most other snakes. However, the closely related $A$. piscivorus has much lower plasma $T$ concentrations than A. contortix (Johnson et al., 1982; Zaidan et al., 2003; Graham et al., 2008), and the congeneric $C$. molossus has substantially lower steroid concentrations than C. atrox (Schuett et al., 2005). The reasons for and implications of differences in absolute steroid concentrations in snakes, whether closely or distantly related, are unknown. 
In snakes with a single annual breeding season, spermatogenesis, maximal $\mathrm{T}$ production, and mating behaviors usually occur simultaneously (e.g., the 'associated' reproductive pattern (Crews, 1984; Whittier \& Crews, 1987)), thereby making it difficult to assess the importance of $T$ in each process. However, studies on those species with bimodal mating seasons suggest that $T$ is responsible for mating behaviors, since $T$ is elevated during both mating periods regardless of whether the testes are spermatogenically active or regressed. Some exceptions are evident: male $V$. aspis sometimes have very low androgen concentrations during mating (Naulleau et al., 1987; Saint Girons et al., 1993). It is important to note that species with two mating seasons are intermediate in the associated/dissociated dichotomy of reproductive patterns (Crews, 1984; Whittier \& Crews, 1987), as they have associated reproduction in one season (late summer/fall) and dissociated reproduction in another (spring) with respect to spermatogenesis. In this context, it is evident that the associated/ dissociated paradigm should be viewed as describing two extremes along a continuum in which many snakes fall somewhere in the middle (Moore \& Lindzey, 1992).

Most research on steroid hormones in snakes has focused on terrestrial snakes from temperate regions, in which reproduction is highly seasonal. A noteworthy exception, however, deserves comment. Gorman et al. (1981) described the seasonal steroid hormone concentrations in relation to reproductive events in three marine snakes (A. granulatus, C. rhynchops, and $L$. colubrina) from the Philippines. These three species show varying degrees of seasonality in their reproductive patterns. A. granulatus is the most seasonal, with mating activity, spermatogenesis, and peak $T$ concentrations occurring in the fall, shortly after vitellogenesis in females. In contrast, $C$. rhynchops, and especially $L$. colubrina, show spermatogenesis throughout the year. Although spermatogenesis and $\mathrm{T}$ concentrations in $C$. rhynchops peak in the fall, there is evidence for year-round gonadal activity. In $L$. colubrina, males show no seasonal trends in spermatogenic activity or $\mathrm{T}$ concentrations. These data suggest that species inhabiting more thermally constant environments, such as the ocean and the tropics, may show year-round reproduction. However, the paucity of data on tropical snakes highlights the need for research in this area.

\subsection{Steroids and Reproduction in Red-sided Garter Snakes (Thamnophis sirtalis parietalis)}

\subsubsection{Females}

Unlike our limited knowledge regarding steroids and reproduction in other species of snake, studies of $T . s$. parietalis go beyond a basic correlational examination between plasma hormone concentrations and the reproductive cycle. Studies of the reproductive endocrinology of $T$. s. parietalis have employed manipulative designs to more closely examine their reproductive endocrinology. Female $T$. $s$, parietalis exhibit a rather unusual relationship between reproductive events and hormones in comparison to other species of snake. Notably, they do not show elevated $\mathrm{P}_{4}$ during gestation (Whittier, Mason, \& Crews, 1987). Like many other snakes studied, plasma $\mathrm{T}$ is elevated during vitellogenesis (Whittier et al., 1987a). Spring mating occurs when $E_{2}$ concentrations are low (Garstka, Camazine, \& Crews, 1982), but Mendonça and Crews (1996) have shown through ovariectomy and hormone replacement therapy that even low $\mathrm{E}_{2}$ concentrations appear to be important in making female snakes attractive and receptive to males. Additionally, the physical act of mating induces a surge in $E_{2}$ in females, but plasma $\mathrm{E}_{2}$ concentrations are not necessarily elevated during vitellogenesis (Garstka, Tokartz, Diamond, Halpert, \& Crews, 1985; Whittier et al., 1987a; Whittier \& Crews, 1989; Mendonça \& Crews, 1990). Copulation, but not courtship, stimulates release of prostaglandin $\mathrm{F}_{2 \alpha}\left(\mathrm{PGF}_{2 \alpha}\right)$ by female $T$. s. parietalis (Whittier \& Crews, 1989). It was hypothesized that this prostaglandin, possibly along with the mating-induced surge in plasma $E_{2}$, causes females to become unreceptive and unattractive to males. This decline in receptivity is effected by cloacal distention during mating, which transmits a neural signal to the brain, and the decline in attractivity is mediated possibly by a pheromone present in copulatory plugs deposited by males (Mendonça \& Crews, 2001).

Whittier (1992) examined the effects of steroid hormones on ovarian and liver tissue in adult female $T . s$. parietalis. Treatment of non-reproductive females with $\mathrm{E}_{2}$ stimulates an increase in oviductal mass and oviductal cell size, but does not affect ovarian mass. 17 $\beta$-estradiol also stimulates an increase in liver mass and hepatocyte size and number. Treatment with $\mathrm{T}$ and DHT stimulates an increase in oviductal mass and oviductal cell size and a slight increase in hepatocyte size and number. These data suggest that $E_{2}$ and androgens, even when not aromatizable (i.e., DHT), can affect the oviduct and to a lesser extent the liver of female $T$. s. parietalis.

\subsubsection{Males}

Male $T$. s. parietalis emerge from communal hibernacula in spring and initiate courtship behavior that lasts several weeks (Crews \& Garstka, 1982). Hawley and Aleksiuk $(1975 ; 1976)$ showed that increased temperatures experienced during spring stimulate reproductive behaviors. Krohmer and Crews (1987a) suggest a possible role for the anterior preoptic area of the hypothalamus (APOA) in this process, as lesions to this area disrupted both courtship behavior and thermoregulation. During spring mating, 
males utilize sperm produced the previous summer and stored through the winter in the vasa deferentia (Krohmer, Grassman, \& Crews, 1987); according to the paradigms described earlier, they therefore exhibit the postnuptial, dissociated reproductive tactic (Crews, 1976). However, studies suggest that $T$. $s$. parietalis also mate in the late summer and fall (Mendonça \& Crews, 1989; Whittier \& Crews, 1989).

It was initially reported that plasma androgen concentrations are low in the spring, when mating occurs (Camazine, Garstka, Tokarz, \& Crews, 1980), again highlighting the postnuptial, dissociated pattern of reproduction in this species. However, later studies demonstrated that androgen concentrations are in fact elevated upon emergence from hibernation but drop rapidly after emergence (Krohmer et al., 1987; Moore, LeMaster, \& Mason, 2000). In accordance with this, the sexual segment of the kidney, which is known to be stimulated by androgens in squamate reptiles (Bishop, 1959), was hypertrophied in the late summer and the spring, but regressed during the summer when androgen concentrations are low (Krohmer et al., 1987). Since there is now evidence for both spring and late summer mating and elevated $\mathrm{T}$ during both fall and emergence from hibernation in spring, this species does not exhibit a strictly dissociated pattern of reproduction. However, mating behavior is not dependent upon $\mathrm{T}$ in male T. s. parietalis (Camazine et al., 1980; Crews, 1984; Crews et al., 1984). Courtship behavior is independent of androgens because castration, adrenalectomy, or hypophysectomy fails to prevent courtship behavior in males, whereas treatment with hypothalamic hormones, GTHs, arginine vasotocin, or sex steroid hormones does not stimulate courtship behavior in adult males (Garstka et al., 1982; Crews et al., 1984). It is possible that prior exposure to androgens organizes brain regions involved in reproduction, and then low temperatures in winter followed by a spring warming activate reproductive behaviors. In support of this hypothesis, $\mathrm{T}$ implants elicit courtship behavior in neonatal and yearling, but not adult, males and females (Crews, 1985). Alternatively, it is possible that androgens play a typical role in gametogenesis in this species but do not play a role in mating behavior, or that their role in mating behavior is yet to be discovered.

\subsection{Hypothalamic Hormones, Gonadotropins, Hormone Receptors, and Binding Globulins in Snakes}

Data on the structure and distribution of gonadotropinreleasing hormone $(\mathrm{GnRH})$ in snakes are scarce and contradictory. Licht et al. (1984) found that chicken and mammalian $\mathrm{GnRH}$ failed to stimulate GTH release in cobras ( N. naja). However, other studies have provided evidence that snakes possess a hormone resembling either mammalian or chicken GnRH. Nozaki, Tsukahara, and Kobayashi (1984) found cell bodies in the hypothalamus and hippocampus of rat snakes (Elaphe climacophora) that were immunoreactive for mammalian GnRH. Sherwood and Whittier (1988) used high performance liquid chromatography to show that $T$. s. parietalis has a single form of GnRH that most closely resembles chicken-I GnRH (cGnRH-I). Smith, Moore, and Mason (1997) examined the distribution of GnRH in the brains of male T. s. parietalis and confirmed that this species has a GnRH resembling the cGnRH-I, with GnRH-like immunoreactivity distributed in many brain regions.

Only a single study has measured concentrations of GTHs in snakes. Bona-Gallo et al. (1980) found that plasma GTH concentrations (detected using a radioimmunoassay with a labeled cobra GTH of unspecified structure) peaked in male $N$. naja during winter, when testicular recrudescence begins. In females, plasma GTH concentrations also peaked in winter, but showed a second peak during spring vitellogenesis. In general, the relationship between GTH concentrations, steroid hormone secretion, and events in the reproductive cycle is not straightforward in this species, leading to the hypothesis that functional changes in gonadal tissue rather than in concentrations of circulating GTHs are responsible for changes in circulating steroid hormone concentrations.

The structure of snake GTHs has yet to be identified, and studies have indirectly assessed the actions of GTHs by evaluating the effects of mammalian GTHs on androgen secretion and testicular development in snakes. Both mammalian follicle-stimulating hormone (FSH) and luteinizing hormone $(\mathrm{LH})$ stimulate gametogenesis, steroid production, and ovulation in snakes (reviewed in Licht, 1974). Tsui and Licht (1977) showed that LH and FSH from various species of vertebrate, including other reptiles, stimulated androgenesis in $C$. atrox and $T . s$. parietalis, but to varying degrees (depending both on the source species of the GTH and the species being tested). This study also suggested that snake GTHs may be structurally divergent from those of many other vertebrates, since snake GTHs failed to elicit androgen production in turtle gonads. Gartska et al. (1985) showed that ovine FSH stimulated hepatic yolk synthesis and yolk deposition into eggs of $T$. s. parietalis. Krohmer (1986) found evidence that ovine FSH stimulates testicular development (e.g., increased testis mass, seminiferous tubule diameters, and epithelial cell size), and ovine $\mathrm{LH}$ stimulates androgenesis in immature water snakes ( $N$. sipedon). Interestingly, however, these effects may depend on season, as bovine LH (but not FSH) stimulates androgenesis in the spring, and bovine FSH (but not $\mathrm{LH}$ ) stimulates androgenesis in the summer and 
fall in adult water snakes (Weil, 1982). Alternatively, ovine and bovine GTHs may be divergent enough in structure to elicit different responses in water snakes, or the differences in the two studies may have to do with the maturity of the snakes. Studies utilizing radioiodinated human FSH showed that this hormone binds readily to snake gonads, and that $\mathrm{LH}$ may act at the same binding site as FSH (Licht \& Midgley, 1976; 1977; Licht et al., 1977; Licht, Farmer, Gallo, \& Papkoff, 1979). Collectively, these studies raised the question as to whether snakes actually have two GTHs, or a single GTH with the actions attributed collectively to FSH and $\mathrm{LH}$ in mammals. Although this question has yet to be answered definitively, a recent study using tissues from the viper Bothrops jaracara successfully cloned the snake FSH receptor (FSHR) but failed to identify a receptor in the $\mathrm{LH}$ receptor family (Bluhm et al., 2004). It is therefore possible that snakes have a single GTH that stimulates gametogenesis, steroid production, and ovulation, or conversely that the snake FSHR possesses moieties distinct from mammal FSHR that account for its apparent lack of discrimination between FSH and LH.

Like studies of GTH receptors, studies of steroid hormone receptors and binding proteins in snakes are limited. Kleis-San Francisco and Callard (1986) identified $\mathrm{P}_{4}$ receptor in the oviduct of Nerodia sp. The presence of a $\mathrm{P}_{4}$ receptor in the oviducts of this viviparous snake may reflect its role in the inhibition of oviductal motility during pregnancy (Callard et al., 1992). Riley and Callard (1988) described a high-affinity, nuclear estrogen receptor in the liver of female Nerodia sp., reflecting the role of this hormone in vitellogenesis in snakes. Only a single study exists on steroid hormone binding proteins (SHBP) in snakes. Riley, Kleis-San Francisco, and Callard (1988) identified a SHBP in Nerodia sp. with a broad binding specificity, binding to $\mathrm{E}_{2}, \mathrm{P}_{4}, \mathrm{~T}, \mathrm{DHT}$, and CORT, with medium-high affinity and limited capacity.

\subsection{The Neuroendocrinology of Reproduction in Snakes}

Most of our current knowledge of the neuroendocrinology of reproduction in snakes comes from studies on $T . s$. parietalis. This species has a distribution of sex steroidresponsive brain neurons similar to other vertebrates (Crews \& Silver, 1985). Researchers have utilized histological techniques, hormone implants, lesioning, and surgical removal techniques to study the roles of the APOA, the ventromedial hypothalamus (VMH), the nucleus sphericus (NS, or amygdala), the septum, and the pineal gland (see Section 3.1) in the regulation of reproduction in T. s. parietalis and a few other species.
Crews, Robker, and Mendonça (1993) found evidence for sexual dimorphism in two brain regions in laboratoryhoused T. s. parietalis: hibernating females have a smaller APOA than hibernating males, and females prevented from hibernating have a smaller NS than males prevented from hibernating. Otherwise, there are no sexual dimorphisms in the brain regions studied. Males show no seasonal or hormone implant-induced variation in APOA, VMH, or NS volume, whereas females show significantly smaller APOA and VMH regions during hibernation than during the rest of the year. Implants of $E_{2}$ stimulated an increase in the size of the preoptic area (POA) of females (Crews et al., 1993).

The APOA is integral in the coordination of stimuli and sexual behaviors in this species (Friedman \& Crews, 1985a; 1985b; Krohmer \& Crews, 1987a), which is typical of vertebrates in general (Crews \& Silver, 1985; Panzica, Viglietti-Panzica, \& Balthazart, 1996). Lesions to the APOA in male $T$. s. parietalis at various times in the annual cycle abolish courtship behavior (Friedman \& Crews, 1985; Krohmer \& Crews, 1987a). These lesions also disrupt thermoregulatory behavior (Krohmer \& Crews, 1987a), and, since exposure to cold winter temperatures followed by heating in spring is essential to the activation of courtship behavior in males (Hawley \& Aleksiuk, 1975; 1976), it is probable that the APOA integrates temperature cues with efferent networks important in courtship behavior.

The NS and the septum appear to play inhibitory roles in courtship behavior in male $T$. s. parietalis, as lesions to these areas facilitate courtship behavior in males (Krohmer \& Crews, 1987b). Lesions to the NS, but not the septum, lead to significant increases in circulating androgens, and lesions to both areas increase the quantity of sexual granules in the sexual segment of the kidney (Krohmer \& Crews, 1987b).

The enzyme aromatase is responsible for converting $\mathrm{T}$ to estrogens, and it is $E_{2}$ rather than $T$ that actually stimulates many male sexual behaviors in vertebrates (Roselli, Horton, \& Resko, 1985; Vagell \& McGuiness, 1997). Therefore, the distribution of aromatase in the male brain can be informative about areas of the brain important in sexual behavior. Krohmer, Bieganski, Baleckaitis, Harada, and Balthazart (2002) found evidence for aromatase immunoreactivity throughout the brain of $T . s$. parietalis, but it was highly concentrated only in the APOA, the NS, and the septum. Since these are the brain areas associated with courtship behavior, local conversion of androgens to $\mathrm{E}_{2}$ may be important in the activation of sexual behavior. This is surprising, considering that studies have repeatedly shown that mating behavior in male $T$. s. parietalis is not dependent on androgens (Camazine et al., 1980; Garstka et al., 1982; Crews, 1984; Crews et al., 1984). This discrepancy has yet to be resolved. 


\section{INFLUENCES ON THE REPRODUCTIVE CYCLE}

\subsection{Environmental Influences}

Environmental stimuli are critical to seasonal reproduction in most animals. In mammals and birds, photoperiod is the primary proximate factor that regulates reproductive activity (reviewed in Dawson, King, Bentley, \& Ball, 2001). However, in snakes and other reptiles, temperature appears to be the primary cue that controls reproductive activity. In T. s. parietalis, the duration of exposure to cold temperatures is critical for stimulating reproduction, whereas photoperiod has inconsistent effects (reviewed in Whittier, Mason, Crews, \& Licht, 1987).

Although the relationship between temperature and reproduction has been known for decades, the hormonal mechanisms by which the interaction operates remain unclear. In cobras (N. naja), hibernation reduces plasma concentrations of numerous hormones, and concentrations return to elevated levels in spring (El-Deib, 2005). Thyroid hormone warrants specific attention as a potential regulator between temperature and reproduction. There is a direct relationship between temperature and iodine uptake by the thyroid (Turner \& Tipton, 1972a), and cold temperatures can also reduce target tissue response to thyroid hormones (Turner \& Tipton, 1972b). As in other taxa, thyroxine $\left(T_{4}\right)$ increases tissue metabolism in snakes (Thapliyal, Kumar, \& Oommen, 1975), but it may also have a direct effect on reproduction. In the most thorough study of $\mathrm{T}_{4}$ and reproduction in snakes, Bona-Gallo et al. (1980) demonstrated a pronounced annual $T_{4}$ cycle with plasma concentrations lowest in winter and substantially elevated during late spring. In males, plasma $T_{4}$ concentrations were elevated when testes mass and plasma $T$ concentrations peaked in May (when females were vitellogenic), but plasma $T_{4}$ concentrations did not actually peak until June, which led the authors to suggest that $T_{4}$ may play a role in testis regression. In females, $\mathrm{T}_{4}$ concentrations peak at the height of ovarian activity (May).

Similarly, in male European adders (V. berus), circulating concentrations of $T_{4}$ are greatest during the period of sexual activity (L. Kelleway, reported in Garstka et al., 1982). However, acutely treating sexually inactive male T. s. parietalis with either $\mathrm{T}_{4}$ or triiodothyronine $\left(\mathrm{T}_{3}\right)$ led to no changes in reproductive activity within 24 hours (Garstka et al., 1982). Interestingly, thyroid-stimulating hormone (TSH) treatment of hypophysectomized male glossy snakes (Arizona elegans) restored spermatogenesis (Chiu \& Lynn, 1971), but the mechanism of this effect was not determined and the effect may simply be a result of cross-reactivity of TSH with GTH receptors. While limited, the data on thyroid hormones hint of a possible role of thyroid hormones in reproduction, including a possible mechanistic link between temperature and reproductive activity.

The pineal gland also deserves specific attention as a potential mediator between environmental conditions and reproduction (Tamarkin, Baird, \& Almeida, 1985; Pang et al., 1998). In reptiles, the pineal gland, through the secretion of melatonin, communicates changes in photoperiod and environmental temperature to the body. In turn, melatonin affects circadian cycles, thermoregulation, and reproductive activity (reviewed in Tosini, 1997). In T. $s$. parietalis, melatonin shows a diel cycle with elevated plasma concentrations during scotophase; however, during hibernation at cold temperatures in total darkness, plasma melatonin is undetectable (Mendonça, Tousignant, \& Crews, 1995). Within hours of emergence, circulating melatonin concentrations peak. In the water snake Nerodia rhombifera, cool temperatures reduce plasma melatonin concentrations and remove the difference in plasma concentration between samples taken during the scotophase and those taken during the photophase despite controlling photoperiod at 12:12 L:D (light: dark) (Tilden \& Hutchison, 1993).

Regarding melatonin's effect on reproductive activity, pinealectomy disrupts gonadal development and regression in Indian chequered water snakes (Natrix piscator) (Haldar \& Pandey, 1989). In T. s. parietalis, males that court during the spring have normal melatonin diel cycles (with increased concentrations during the scotophase), whereas males that do not court have reversed diel cycles (Mendonça, Tousignant, \& Crews, 1996a). Pinealectomizing males prior to hibernation reduces courtship behavior the following spring (Nelson, Mason, Krohmer, \& Crews, 1987; Crews, Hingorani, \& Nelson, 1988; Mendonça et al., 1996a). Further, treatment with exogenous melatonin inhibits courtship behavior (Lutterschmidt, LeMaster, \& Mason, 2004). Together, these results demonstrate that gonadal development and courtship behavior depend on normal diel cycles of melatonin. However, pinealectomy in spring does not alter existing courtship behavior, suggesting that melatonin cycles are critical for providing the initial stimulus for courtship but not for modulating courtship once initiated (Mendonça, Tousignant, \& Crews, 1996b). Seasonal melatonin cycles vary among Thamnophis sirtalis populations with differing climate conditions and courting cycles, although the relationship between the inter-population variations in melatonin and courtship is unclear (Lutterschmidt \& Mason, 2008).

\subsection{Social Influences}

Although descriptive studies on seasonal hormonal cycles in snakes have been conducted in numerous species, it is remarkable that studies that manipulate sex steroid profiles are almost completely limited to studies of $T$. $s$. parietalis. 
As a result, knowledge of how specific reproductive behavioral components (e.g., attractivity, courtship, receptivity, copulation) are regulated and how these events influence the hormonal milieu of the individuals experiencing them comes almost exclusively from this species.

In $T$. $s$. parietalis, mating occurs at the time of emergence when both males and females have low plasma concentrations of sex steroids (reviewed in Mendonça \& Crews, 1996). The onset of male courtship behavior seems to be independent of $\mathrm{T}$, and, instead, dependent on warming upon post-hibernation emergence (Hawley \& Aleksiuk, 1975 ; 1976). In fact, males that have been castrated for as long as three years will still court females after emergence from hibernation. Courting by males is enhanced by the presence of other males (Joy \& Crews, 1985). In females, attractivity is not affected by ovariectomy during either the fall or the hibernation period preceding emergence, but is abolished when females are ovariectomized the spring prior to emergence. Receptivity, on the other hand, is inhibited by ovariectomy at any of the three time points. Receptivity was reinstated in ovariectomized females that were given exogenous $E_{2}$ one hour prior to emergence, but not in females treated approximately one week after emergence (Mendonça \& Crews, 1996). Thus, reproductive behavior of the two sexes seems to be regulated by different stimuli. Male courting is hormonally independent and driven by environmental cues (both thermal and social) while female reproductive behavior is affected by a combination of environmental conditions and the presence of at least low levels of $E_{2}$. It is important to reiterate that the seasonal hormonal patterns of other snake species can differ greatly from those of T. s. parietalis (see Section 2), and thus the hormonal and social effects on reproductive behavior in this discussion, which is based predominantly on $T$. $s$. parietalis, should not be broadly applied to snakes in general.

Whereas environmental stimuli tend to regulate the seasonality of reproduction, social cues often fine tune the timing of reproduction. Snakes are mostly solitary animals, and thus locating a mate is not a foregone conclusion. To facilitate mate acquisition, it has been demonstrated in many species that females produce pheromones that enable males to trail them (LeMaster, Moore, \& Mason, 2001; Chapter 6, this volume). Methyl ketones secreted from the skin of the female's dorsum are also critical to female attractivity and induce intensive courtship by males (reviewed in Mason 1993; Mason et al., 1989). These sexual signals are highly specific and thus can contribute both to species isolation (Ford \& O'Bleness, 1986; Mason, 1993; Shine, Reed, Shetty, LeMaster, \& Mason, 2002; Shine, Phillips, Waye, LeMaster, \& Mason, 2004) and population isolation (LeMaster \& Mason, 2003), as well as enable males to distinguish female body size (LeMaster \& Mason, 2002) and female mating history (O’Donnell, Ford,
Shine, \& Mason, 2004), and orient copulatory posture (Shine, O'Connor, \& Mason, 2000a). Additionally, male snakes possess skin lipids that inhibit female pheromoneinduced courtship by other males (Mason et al., 1989).

Brown treesnakes (Boiga irregularis) are atypical in that both males and females show courtship behavior (Greene \& Mason, 2000). In this species, females use a combination of an attractiveness pheromone and an inhibitory pheromone, the latter of which is present in cloacal secretions, to regulate courtship by males; however, cloacal secretions from males or females do not inhibit female courtship (Greene \& Mason, 2003).

The act of copulation leads to numerous physiological changes. As sperm have been delivered during copulation, future copulations are of much less value to the female and would negatively affect the reproductive success of the first male (but see review on multiple paternity in reptiles by Uller and Olsson (2008)). The ejaculate of male T. $s$. parietalis contains secretory granules from the renal sex segment that combine with cloacal secretions from the female to form a gelatinous copulatory plug at the oviductal-cloacal junction. Copulatory plugs are relatively rare among snakes, and may reflect costs associated with high density mating aggregations (reviewed in Uribe, González-Porter, Palmer, \& Guillette, 1998). The copulatory plug provides a temporary physical barrier against future matings. Inhibition of attractivity is apparently a result of chemical cues in the semen, as females smeared on the back with semen, but not ones smeared with a copulatory plug, failed to elicit courting responses from males (Shine, Olsson, \& Mason, 2000). Although the seminal chemical cues have not yet been identified, it has been proposed that $\mathrm{PGF}_{2 \alpha}$ may play a role. Prostaglandin $F_{2 \alpha}$ is present in the semen of other vertebrates. Female plasma concentrations of $\mathrm{PGF}_{2 \alpha}$ are elevated immediately after copulation in $T$. s. parietalis, and injection of $\mathrm{PGF}_{2 \alpha}$ decreases attractivity and receptivity in unmated females. Mechanical stimulation of the reproductive tract can stimulate endogenous release of prostaglandins, and thus the female may provide an alternate or additional source of $\mathrm{PGF}_{2 \alpha}$ (reviewed in Mendonça \& Crews, 2001). Regardless of whether $\mathrm{PGF}_{2 \alpha}$ is involved, physical stimulation of the cloaca is important in altering attractivity and receptivity at copulation in T. s. parietalis (reviewed in Mendonça \& Crews, 2001). More recent work has demonstrated that sensory input from the cloaca at copulation alters patterns of metabolism in the VMH, an area of the brain often associated with female sexual behavior (Mendonça, Daniels, Faro, \& Crews, 2003).

In addition to playing a role in altering attractivity and receptivity, physical cues during mating stimulate progression of reproductive activity in the ovary. Shortly after copulation, female $T$. s. parietalis have a surge in plasma $E_{2}$ and undergo ovarian recrudescence. These 
responses can be prevented by removal of cloacal sensation via spinal transection or the application of local anesthetic prior to mating (Mendonça \& Crews, 1990). Similarly, female blood pythons (Python curtus) will not undergo vitellogenic growth of follicles without the presence of, and likely copulation by, a male (DeNardo \& Autumn, 2001). It is intriguing that, at least in these two distantly related species, males are involved in promoting early follicular growth despite the fact that sperm is not needed for fertilization until weeks later, at ovulation. However, some female $T . s$. parietalis undergo ovarian recrudescence without mating in spring, at least in some years (reviewed in Mendonça \& Crews, 1990).

The predominant social influences on reproduction are a result of male-female interactions, but male-male interactions can also alter reproductive activity. Although snakes neither form social groups nor defend established territories, encounters between two males can lead to agonistic interactions. Male-male combat is widespread among snakes (Shine, 2003), with the combat of viperid snakes being the best documented. In $V$. berus, chemical signals from the female elicit courtship by males, whereas other skin-derived chemical cues from the male appear to induce combat behavior (Andrén, 1986). Among crotaline snakes, combat is very ritualistic. In the copperhead (A. contortrix), individuals that lose combats not only flee the site, but courtship remains inhibited for at least 24 hours (Schuett, 1996). These combat losers have increased plasma CORT concentrations, which may provide a mechanistic link between combat loss and courtship suppression (Schuett, 1996; Schuett \& Grober, 2000).

A fascinating male-male interaction exists in the unique mating system of $T$. s. parietalis. This species shows no male-male aggression, but instead some males act as 'she-males' that exhibit altered courtship behavior and are attractive to other males (Mason \& Crews, 1985). The significance of this reproductive strategy is unclear. It was initially postulated that 'she-maleness' is relatively permanent and may serve as a distractant to other males present in the mating ball and thus enhance the mating success of the she-male (Mason \& Crews, 1985). More recently, Shine, Harlow, LeMaster, Moore, \& Mason (2000) described the scenario where she-maleness is a transient stage of recently emerged males, since they have poor locomotory performance and thus would not be competitive against other males in accessing copulations. By being she-males, newly emerged snakes would not waste energy on fruitless courting and they would also induce other males to waste energy by courting the shemales (Shine et al., 2000c). Regardless of the ultimate strategy, the she-male phenomenon, including both the inhibition of courting behavior and the attractiveness of she-males to other males, is driven by male production of a pheromone similar to that of females (Mason \& Crews,
1985; Shine et al., 2000c). The regulatory mechanism for the production of this pheromone is not known, but it may involve $\mathrm{T}$, since she-males have higher plasma $\mathrm{T}$ concentrations than do normal males (Mason \& Crews, 1985). Additionally, the involvement of brain aromatase should be considered, since snakes collected from the den in early winter show high concentrations of aromatase in brain regions involved in the control of courtship and mating (Krohmer et al., 2002).

\subsection{Physiological Influences}

Beyond environmental and social influences, reproductive activity is also influenced by non-reproductive aspects of the individual. Because of the high energy demand associated with reproduction, body condition is especially important in influencing the reproductive activity of snakes. Many snakes use a capital breeding strategy rather than one of income breeding (reviewed in Gregory, 2006). That is, in capital breeders, reproductive activity is based on energy reserves more so than current food intake (Drent \& Daan, 1980). In capital breeders, females need to attain a minimum threshold of body condition prior to committing to a reproductive event, although this threshold may vary among years (Naulleau \& Bonnet, 1996; Madsen \& Shine, 1999).

The relationship between body condition and reproductive activity is well-established; however, little is known about the hormonal regulation of this relationship in snakes. In V. aspis, females in poor body condition have low circulating $E_{2}$ concentrations and are not sexually receptive, but once a female is beyond a critical threshold of body reserves, she exhibits elevated plasma $\mathrm{E}_{2}$ concentrations and is receptive (Aubret, Bonnet, Shine, \& Lourdais, 2002). Males, however, do not show a threshold response, as all males had detectable plasma $\mathrm{T}$ concentrations and displayed courtship behavior, but both plasma $\mathrm{T}$ and courtship behavior increased proportionately with body condition (Aubret et al., 2002). The hormone leptin might be considered an important link between energy state and reproduction. Leptin occurs in a diverse group of vertebrates and is known, at least in mammals, to be involved in the energy stores-reproduction relationship (reviewed in Paolucci, Rocco, \& Varricchio, 2006) and might play a similar role in snakes.

In addition to body reserves influencing reproduction, many snake species show size-dependent fecundity with larger females producing a greater clutch mass (Ford \& Seigel, 1989; Madsen \& Shine, 1994, but see Lourdais et al., 2002). This relationship can lead to sexual size dimorphism with females being larger than males. Many factors including age, food intake, and possibily hormones can affect growth rate and body size (reviewed in Taylor \& DeNardo, 2005) and thus influence sexual size dimorphism. 
There is some evidence that, in $T$. sirtalis, where females are larger than males, estrogens promote growth while $\mathrm{T}$ suppresses it (Crews, Diamond, Whittier, \& Mason, 1985; Lerner \& Mason, 2001).

Stress is also known to have a dramatic effect on reproduction in reptiles, including snakes (reviewed in Moore \& Jessop, 2003; Chapter 7, this volume). Commonly, stress negatively influences reproduction, either through direct or indirect effects of elevated CORT on reproductive hormones or other components of the reproductive system (Wingfield et al., 1998). In brown treesnakes (B. irregularis), capture and placement in outdoor enclosures under ambient conditions terminates spermatogenesis and development of the sexual segment of the kidney (Aldridge \& Arackal, 2005). Plasma steroids were not assessed in this study; however, trapping and confinement of $B$. irregularis leads to in an increase in plasma CORT concentrations (Mathies, Felix, \& Lance, 2001). Further, elevated plasma CORT was thought to explain, at least in part, low reproductive activity in a freeliving population of $B$. irregularis on Guam (Moore et al., 2005). Apparently, however, $B$. irregularis can acclimate to captivity, as individuals held long-term in captivity are reproductively active and have low plasma CORT concentrations (Moore et al., 2005).

The susceptibility of an animal to stress can vary seasonally. Unlike $B$. irregularis, which has an extended breeding season, $T$. s. parietalis in Manitoba, Canada, has an extremely short reproductive period. During the nonbreeding summer, males respond to capture stress with elevated CORT and reduced T. However, during the primary reproductive period in spring and the secondary mating and pre-hibernation period in fall, the hormonal response to stress is variable but, in general, reduced (Moore, Greene, \& Mason, 2001; Lutterschmidt \& Mason, 2005; but see Moore et al., 2000). In the conspecific redspotted garter snake (Thamnophis sirtalis concinnus), which has an extended breeding season in Oregon, capture during the reproductive season induces the classical stress response of increasing CORT while decreasing $\mathrm{T}$ (Moore et al., 2001; Lutterschmidt et al., 2004). Interestingly, in the one study in which capture induced an elevated CORT response in the Manitoba population of $T . s$. parietalis during the breeding season, there was no effect on courtship behavior (Moore et al., 2000). However, in separate studies, exogenous treatment with CORT inhibits courting (Moore and Mason, 2001; Lutterschmidt et al., 2004). Although inconsistencies exist, the overall conclusion from these studies is that, like other vertebrates, snakes haves a classical stress response, but the hormonal and or behavioral response may be attenuated during the reproductive season for populations in which reproductive opportunities are limited. Surprisingly, the shift from non-responsiveness to responsiveness to capture stress can be abrupt, as the classical hormonal response to capture stress is intact in male $T$. $s$. parietalis that are dispersing from the mating sites to feeding sites (Cease, Lutterschmidt, \& Mason, 2007).

Analyzing the effects of CORT as a modulator for the stress response (and thus an inhibitor of reproduction) is complicated by CORT's most basic function as an energy mobilization hormone. As such, elevated CORT may augment reproduction (reviewed in Moore \& Jessop, 2003). In male $T$. $s$. parietalis, baseline plasma CORT concentrations are elevated during the spring breeding season (Moore et al., 2001), and it is thought that this elevated CORT facilitates reproduction by mobilizing much-needed energy stores to sustain costly courtship activity during this period of aphagia (Moore \& Jessop, 2003).

\subsection{Embryonic Influences}

Nearly all studies of snake reproductive endocrinology have examined the relationships between behavior, physiological state, and hormones in adults, but it is important to at least briefly consider the embryonic snake. Many reptiles, including lizards, are known to have environmental sex determination in which environmental conditions, particularly temperature, influence sex by altering embryonic hormone exposure. Environmental sex determination has not been identified in any snake (reviewed in Janzen \& Paukstis, 1991). However, exposure of embryos to steroids may alter other embryonic traits. Corticosterone treatment of gravid female Thamnophis elegans led to reduced embryonic and early offspring survivorship as well as changes in morphological and behavioral characteristics of the offspring (Robert, Vleck, \& Bronikowski, 2009). Also in T. elegans, prenatal sex ratio affects subcaudal scale counts of female offspring in one of two populations (Osypka \& Arnold, 2000). Although limited, these studies together suggest that snakes are susceptible to the influences of sex steroids prior to birth.

\section{FUTURE DIRECTIONS TO AUGMENT EXISTING KNOWLEDGE}

As snakes are a distinct suborder of vertebrates with nearly 3000 species, it is important that we obtain a thorough understanding of their reproductive endocrinology. It is imperative that we distinguish traits that are relatively conserved among snakes from those that may be unique to individual species or small groups of species. Thus, we are in great need of data from a larger diversity of snake species. Currently, the reproductive endocrinology of snakes is grossly biased (and possibly misrepresented) by data from a single species, $T . s$. parietalis. Studies of $T . s$. parietalis have led the way in our understanding of snake reproductive endocrinology, and such leadership in the field 
must continue. However, evaluating large taxonomic groups based on the study of a single species is dangerous. Applying findings based on studies of $T$. $s$. parietalis to snakes in general may be especially problematic given that $T$. s. parietalis has numerous traits that are atypical of most snakes, including its high latitude, cold climate distribution, and its mating system in which reproduction entails massive mating balls formed immediately at female emergence. Strong bias resulting from the evaluation of a single or few species to represent larger taxonomic groups is unfortunately not unique to snakes, as 'frog' physiology is largely based on data from the African clawed frog (Xenopus laevis) or American bullfrog (Lithobates (Rana) catesbeiana) and 'turtle' physiology on red-eared sliders (Trachemys scripta). Even avian and mammalian physiology are biased by studies on the domestic chicken (Gallus gallus) and on the laboratory mouse (Mus musculus) and rat (Rattus norvegicus), respectively. The bias regarding snake study species goes beyond $T$. s. parietalis in that data from other species come disproportionately from temperate species, particularly viperids. There is a great need for studies of the reproductive endocrinology of tropical snakes and snakes other than Viperidae and Colubridae (e.g., Scolecophidia, basal Alethinophidia, and the speciose Elapidae).

Beyond being a relatively large taxonomic group, snakes show diverse reproductive strategies, and this diversity provides a unique opportunity for comparative studies to better understand reproductive endocrinology of vertebrates in general. Data collected thus far strongly indicate that snakes utilize a hypothalamic-pituitarygonadal hormonal axis similar to that of other vertebrates, at least on a broad scale. However, the diversity of reproductive tactics within the squamates (lizards and snakes) is unmatched by other major terrestrial taxonomic groups. While the group is ancestrally oviparous, viviparity has evolved over 100 times among squamates (Shine, 1985). Additionally, some squamates, including snakes, are parthenogenic, with the ability to produce offspring asexually. Parthenogenesis is best documented as a result of hybridization and polyploidy and thus an obligate process (reviewed in Dowling \& Secor, 1997). Such forms of parthenogenesis have been well documented in lizards (e.g., particularly in lizards of the genus Aspidoscelis (Price, LaPointe, \& Atmar, 1993)) as well as the blind snake Ramphotyphlops braminus (Ota, Hikida, Matsui, Mori, \& Wynn, 1991). However, numerous squamates including snake species are capable of facultative parthenogenesis (Dubach, Sajewicz, \& Pawley, 1997; Schuett et al., 1997b; Groot, Bruins, \& Breeuwer, 2003). That is, species that are diploid and normally sexually reproductive can, at times, reproduce asexually, producing diploid offspring. Interestingly, there appear to be inter-species differences in the mechanism by which diploidy is maintained despite meiosis, since in some species only males are produced while in others only females result (reviewed in Groot et al., 2003). While understanding the mechanisms for such unique reproduction among vertebrates may prove extremely valuable to identifying the regulators of snake reproduction, studies on facultative parthenogenesis are logistically difficult because it is not known what stimulates females to reproduce asexually rather than foregoing reproduction when a mate is not present. Similarly valuable, but less extreme physiologically, are the variations in the timing and frequency of reproduction among snakes. Specific environmental cues (e.g., increasing temperatures after a cool period) are thought to be critical in regulating snake reproductive cycles. However, some species can have multiple reproductive events in a given year and under different environmental conditions. The reproductive events may be limited to multiple mating periods (e.g., as described earlier for many rattlesnakes) or entail the production of multiple clutches. Multiple clutch production is typically limited to captive snakes (Ford \& Seigel, 2006), although it has been documented in wild keelbacks, Tropidonophis mairii (Brown \& Shine, 2002). This does not negate the value in using that potential to understand reproductive stimuli in snakes.

To more fully examine the details of snake reproductive endocrinology, it is imperative that studies move away from the predominant use of descriptive studies and utilize manipulative experiments. Only in $T . s$. parietalis have a considerable number of manipulative studies been conducted to better understand the causal relationships between reproductive behavior, gonad function, and hormones. Potential manipulative approaches are numerous and range from hormone modulation (e.g., organ removal, hormone treatment, hormone antagonist treatment), to modification of organism state (e.g., energy balance, water balance, stress, function of senses), to environmental manipulation (e.g., temperature, photoperiod, humidity, rainfall, pheromonal cues, social structure). Conducting such experiments in both the laboratory where variables can be more tightly controlled and in the field where conditions are more natural will be essential.

Given that data thus far collected suggest that the snake reproductive axis is generally similar to that of other vertebrates, it is not too risky to presume that stimuli for reproductive activity act through the brain. Unfortunately, literature on the reproductive neuroendocrinology of snakes is extremely limited. It is astounding that we do not yet know which, or even how many, GTHs exist in any snake, let alone among snakes.

Our knowledge of snake hypothalamic hormones involved in reproduction is nearly non-existent. Although multiple variants of the GnRH decapeptide exist among vertebrates, only chicken-I GnRH has been identified, and 
only from a single snake species: not surprisingly, $T$. $s$. parietalis (Sherwood \& Whittier, 1988; Smith et al., 1997). The failure to detect other $\mathrm{GnRH}$ variants from snakes is likely due to a lack of effort more than the variants not being present, since mammalian GnRH has yet to be identified in any reptile despite its presence in fishes, amphibians, and mammals (King \& Millar, 1997). Similarly, gonadotropin-inhibiting hormone $(\mathrm{GnIH})$ has yet to be found in any reptile. Since its recent discovery in quail (Tsutsui et al., 2000), GnIH has been identified in multiple species of fishes, birds, and mammals (reviewed in Ubuka, McGuire, Calisi, Perfito, \& Bentley, 2008; Volume 4, Chapter 2). Despite its novelty, gonadotropin-inhibiting hormone is potentially an important regulator of reproduction, and thus a thorough understanding of the regulation of reproduction in snakes is likely impossible without the consideration of GnIH.

Numerous other hormones are worthy of study to assess their roles in snake reproduction. Hormones such as prolactin ( $\mathrm{Ng}$, Lee, Cheng, \& Wong, 1990), arginine vasotocin (Silveira, Schiripa, Carmona, \& Picarelli, 1992), and growth hormone ( $\mathrm{Ng}$, Lee, Cheng, \& Wong, 1993) have been identified in at least one snake species, yet their potential roles in reproduction have thus far been completely ignored. Hormones such as leptin and relaxin have yet to even be identified in snakes, yet their existence is likely considering their presence among diverse vertebrates.

One final area of study that has received considerable attention in other taxa, especially birds, is that of maternal transfer of sex steroids to offspring via the yolk. Since initially described by Schwabl (1993), maternal steroid transfer has been shown to have dramatic effects on offspring phenotype (reviewed in Radder \& Shine, 2007), although the mechanisms of transfer between the female and the yolk as well as the yolk and the embryo are poorly understood (Moore \& Johnston, 2008). Despite this broad attention, the demonstrated biological importance of yolk transfer has yet to be explored in snakes.

Clearly, the study of snake reproductive endocrinology is in its infancy. Regardless, contributions by numerous investigators have expanded our understanding over the last several decades. It is essential to build on this foundation, as doing so will not only provide comparative data, but provide knowledge that can be utilized to assist in efforts to ensure species persistence as well as enhance general knowledge of reproductive endocrinology across all vertebrates.

\section{ACKNOWLEDGEMENTS}

We thank M. Rockwell Parker and Gordon W. Schuett for reviewing drafts of this manuscript.

\section{ABBREVIATIONS}

APOA Anterior preoptic area of the hypothalamus

CORT Corticosterone

DHT Dihydrotestosterone

$\mathbf{E}_{2} \quad 17 \beta$-estradiol

FSH Follicle-stimulating hormone

FSHR Follicle-stimulating hormone receptor

GnIH Gonadotropin-inhibiting hormone

GnRH Gonadotropin-releasing hormone

GTH Gonadotropin

LH Luteinizing hormone

NS Nucleus sphericus

$\mathbf{P}_{4} \quad$ Progesterone

PGF $_{2 \alpha}$ Prostaglandin $F_{2 \alpha}$

POA Preoptic area

SHBP Steroid hormone-binding protein

T Testosterone

$\mathbf{T}_{\mathbf{3}} \quad$ Triiodothyronine

$\mathbf{T}_{\mathbf{4}} \quad$ Thyroxine

TSH Thyroid-stimulating hormone

VMH Ventromedial hypothalamus

\section{REFERENCES}

Aldridge, R. D., \& Arackal, A. A. (2005). Reproductive biology and stress of captivity in male brown treesnakes (Boiga irregularis) on Guam. Aust. J. Zool., 53, 249-256.

Aldridge, R. D., Greenhaw, J. J., \& Plummer, M. V. (1990). The male reproductive cycle of the rough green snake (Opheodrys aestivus). Amphibia-Rep., 11, 165-172.

Almeida-Santos, S. M., Abdalla, F. M. F., Silveira, P. F., Yamanouye, N., Breno, \& Salomão, M. G. (2004). Reproductive cycle of the Neotropical Crotalus durissus terrificus: I. Seasonal levels and interplay between steroid hormones and vasotocinase. Gen. Comp. Endocrinol., 139, 143-150.

Andrén, C. (1986). Courtship, mating and agonistic behaviour in a freeliving population of adders, Vipera berus (L.). Amphibia-Rep., 7, $353-383$.

Aubret, F. Bonnet, X., Shine, R., \& Lourdais, O. (2002). Fat is sexy for females but not males: the influence of body reserves on reproduction in snakes (Vipera aspis). Horm. Behav, 42, 135-147.

Bishop, J. E. (1959). A histological and histochemical study of the kidney tubule of the common garter snake, Thamnophis sirtalis, with special reference to the sexual segment in the male. J. Morphol, 104, $307-358$.

Bluhm, A. P. C., Toledo, R. A., Mesquita, F. M., Pimenta, M. T., Fernandes, F. M. C., Ribela, M. T. C. P., \& Lazari, M. F. M. (2004). Molecular cloning, sequence analysis and expression of the snake follicle-stimulating hormone receptor. Gen. Comp. Endocrinol, 137, 300-311.

Bona-Gallo, A., Licht, P., MacKenzie, D. S., \& Lofts, B. (1980). Annual cycles in pituitary and plasma gonadotropin, gonadal steroids, and thyroid activity in the Chinese cobra (Naja naja). Gen. Comp. Endocrinol., 42, 477-493.

Bonnet, X., Naulleau, G., Bradshaw, D., \& Shine, R. (2001). Changes in plasma progesterone in relation to vitellogenesis and gestation in the viviparous snake Vipera aspis. Gen. Comp. Endocrinol., 121, 84-94. 
Brown, G. P., \& Shine, R. (2002). Reproductive ecology of a tropical natricine snake Tropidonophis mairii (Colubridae). J. Zool. Lond., $258,63-72$.

Callard, I. P., Fileti, A. L., Perez, L. E., Sobrera, L. A., Giannoukos, G., Klosterman, P. T., \& McCracken, J. A. (1992). Role of the corpus luteum and progesterone in the evolution of vertebrate viviparity. Amer. Zool., 32, 264-275.

Callard, I. P., Giannoukos, G., Charnock-Jones, D. S., Benson, S., \& Paolucci, M. (1994). Hormone regulation of vitellogenin genes and the evolution of viviparity. In K. G. Davey, R. E. Peter, \& S. S. Tobe (Eds.), "Perspectives in Comparative Endocrinology" (pp. 325-332). Ottawa, Canada: National Research Council of Canada.

Camazine, B., Garstka, W., Tokarz, R., \& Crews, D. (1980). Effects of castration and androgen replacement on male courtship behavior in the red-sided garter snake (Thamnophis sirtalis parietalis). Horm. Behav, 14, 358-372.

Cease, A. J., Lutterschmidt, D. I., \& Mason, R. T. (2007). Corticosterone and the transition from courtship behavior to dispersal in male redsided garter snakes (Thamnophis sirtalis parietalis). Gen. Comp. Endocrinol., 150, 124-131.

Chiu, K. W., \& Lynn, W. G. (1971). The hypophysis-gonad relation in the glossy snake, Arizona elegans. Herpetologica, 27, 303-307.

Crews, D. (1976). Hormonal control of male courtship behavior and female attractivity in the garter snake (Thamnophis sirtalis parietalis). Horm. Behav., 7, 451--460.

Crews, D. (1984). Gamete production, sex hormone secretion, and mating behavior uncoupled. Horm. Behav., 18, 22-28.

Crews, D. (1985). Effects of early sex steroid treatment on courtship behavior and sexual attractivity in the red-sided garter snake, Thamnophis sirtalis parietalis. Physiol. Behav., 35, 569-575.

Crews, D., \& Garstka, W. (1982). The ecological physiology of a garter snake. Sci. Amer., 247, 158-168.

Crews, D., \& Silver, R. (1985). Reproductive physiology and behavior interactions in nonmammalian vertebrates. In N. Alder, D. Pfaff, \& R. W. Goy (Eds.), "Handbook of Behavioral Neurobiology", Vol. 7 (pp. 101-182). New York: Plenum.

Crews, D., Camazine, B., Diamond, M., Mason, R., Tokarz, R. R., \& Garstka, W. R. (1984). Hormonal independence of courtship behavior in the male garter snake. Horm. Behav., 18, 29-41.

Crews, D., Diamond, M. A., Whittier, J., \& Mason, R. T. (1985). Small male body size in garter snake depends on testes. Am. J. Physiol., 249, R62-R66.

Crews, D., Hingorani, V., \& Nelson, R. J. (1988). Role of the pineal gland in the control of annual reproductive behavioral and physiological cycles in the red-sided garter snake (Thamnophis sirtalis parietalis). J. Biol. Rhythms., 3, 293-302.

Crews, D., Robker, R., \& Mendonça, M. (1993). Seasonal fluctuations in brain nuclei in the red-sided garter snake and their hormonal control. J. Neurosci., 13, 5356-5364.

Custodia-Lora, N., \& Callard, I. P. (2002). Progesterone and progesterone receptors in reptiles. Gen. Comp. Endocrinol., 127, 1-7.

Dawson, A., King, V. M., Bentley, G. E., \& Ball, G. F. (2001). Photoperiodic control of seasonality in birds. J. Biol. Rhythm., 16, 365-380.

DeNardo, D. F., \& Autumn, K. (2001). The effect of male presence on reproductive activity in captive female blood pythons, Python curtus. Copeia, 2001, 1138-1141.
Dowling, T. E., \& Secor, C. L. (1997). The role of hybridization and introgression in the diversification of animals. Annu. Rev. Ecol. Syst., $28,593-619$.

Drent, R. H., \& Daan, S. (1980). The prudent parent: energetic adjustments in avian breeding. In H. Klomp, \& J. W. Woldendorp (Eds.), "The Integrated Study of Bird Populations" (pp. 225-252). Amsterdam: North Holland.

Dubach, J., Sajewicz, A., \& Pawley, R. (1997). Parthenogenesis in the Arafuran filesnake (Acrochordus arafurae). Herpetol. Nat. Hist., 5, 11-18.

Dunham, A. E., Miles, D. B., \& Reznick, D. N. (1988). Life-history patterns in squamate reptiles. In C. Gans, \& R. B. Huey (Eds.), "Biology of the Reptilia, Vol. 16, Ecology B, Defense and Life History" (pp. 471-511). NY: Alan R. Liss, Inc.

Duvall, D., Arnold, S. J., \& Schuett, G. W. (1992). Pitviper mating systems: Ecological potential, sexual selection, and microevolution. In J. A. Campbell, \& E. D. Brodie, Jr. (Eds.), "Biology of the Pitvipers" (pp. 321-336). Texas: Selva, Tyler.

El-Deib, S. (2005). Serum catecholamine and hormonal titers in the hibernating snake Naja haje haje, with reference to the annual climatic cycle. J. Therm. Biol., 30, 580-587.

Ford, N. B., \& O'Bleness, M. L. (1986). Species and sexual specificity of pheromone trails of the garter snake, Thamnophis marcianus. J. Herpetol., 20, 259-262.

Ford, N. B., \& Seigel, R. A. (1989). Relationships among body size, clutch size, and egg size in three species of oviparous snakes. Herpetologica, 45, 75-83.

Ford, N. B., \& Seigel, R. A. (2006). Intra-individual variation in clutch and offspring size in an oviparous snake. J. Zool., 268, 171-176.

Friedman, D., \& Crews, D. (1985a). Role of anterior hypothalamuspreoptic area in the regulation of courtship behavior in the male Canadian red-sided garter snake (Thamnophis sirtalis parietalis): Lesion study. Behav. Neurosci., 99, 942-949.

Friedman, D., \& Crews, D. (1985b). Role of the anterior hypothalamuspreoptic area in the regulation of courtship behavior in the male Canadian red-sided garter snake (Thamnophis sintalis parietalis): Intracranial implantation experiments. Horm. Behav., 19, 122-136.

Garstka, W. R., Camazine, B., \& Crews, D. (1982). Interactions of behavior and physiology during the annual reproductive cycle of the red-sided garter snake (Thamnophis sirtalis parietalis). Herpetologica, 38, 104-123.

Garstka, W. R., Tokartz, R. R., Diamond, M., Halpert, A., \& Crews, D. (1985). Behavioral and physiological control of yolk synthesis and deposition in the female red-sided garter snake (Thamnophis sirtalis parietalis). Horm. Behav., 19, 137-153.

Gorman, G. C., Licht, P., \& McCollum, F. (I981). Annual reproductive patterns in three species of marine snakes from the central Phillippines. J. Herpetol., 15, 335-354.

Graham, S. P., Earley, R. L., Hoss, S. K., Schuett, G. W., \& Grober, M. S. (2008). The reproductive biology of male cottonmouths (Agkistrodon piscivorus): Do plasma steroid hormones predict the mating season? Gen. Comp. Endocrinol., 159, 226-235.

Greene, M. J., \& Mason, R. T. (2000). Courtship, mating, and male combat of the brown tree snake, Boiga irregularis. Herpetologica, 56, $166-175$.

Greene, M. J., \& Mason, R. T. (2003). Pheromonal inhibition of male courtship behaviour in the brown tree snake, Boiga irregularis: a mechanism for the rejection of potential mates. Anim. Behav., 65 , 905-910. 
Gregory, P. T. (2006). Influence of income and capital on reproduction in a viviparous snake: direct and indirect effects. J. Zool., 414-419.

Groot, T. V. M., Bruins, E., \& Breeuwer, J. A. J. (2003). Molecular genetic evidence for parthenogenesis in the Burmese python, Python molurus bivittatus. Heredity, 90, 130-135.

Haldar, C., \& Pandey, R. (1989). Effect of pinealectomy on annual testicular cycle of Indian chequered water snake, Natrix piscator. Gen. Comp. Endocrinol., 76, 214-222.

Hawley, A. W. L., \& Aleksiuk, M. (1975). Thermal regulation of spring mating behavior in the red-sided garter snake (Thamnophis sirtalis parietalis). Can. J. Zool., 53, 768-776.

Hawley, A. W. L., \& Aleksiuk, M. (1976). The influence of photoperiod and temperature on seasonal testicular recrudescence in the red-sided garter snake (Thamnophis sirtalis parietalis). Comp. Biochem. Physiol., 53A, 401-404.

Ho, S. M., Kleis-San Francisco, S., McPherson, R., Heiserman, G. J., \& Callard, I. P. (1982). Regulation of vitellogenesis in reptiles. Herpetologica, 38, 40-50.

Janzen, F. J., \& Paukstis, G. L. (1991). Environmental sex determination in reptiles: ecology, evolution, and experimental design. Q. Rev. Biol., $66,149-179$.

Johnson, L. F., Jacob, J. S., \& Torrance, P. (1982). Annual testicular and androgenic cycles of the cottonmouth (Agkistrodon piscivorus) in Alabama. Herpetologica, 38, 16-25.

Joy, J. E., \& Crews, D. (1985). Social dynamics of group courtship behavior in male red-sided garter snakes (Thamnophis sirtalis parietalis). J. Comp. Psych., 99, 145-149.

King, J. A., \& Millar, R. P. (1997). Coordinated evolution of GnRHs and their receptors. In I. S. Parhar, \& Y. Sakuma (Eds.), "GnRH Neurons: Gene to Behavior" (pp. 51-78). Tokyo: Brain Shupan.

Kleis-San Francisco, S. M., \& Callard, I. P. (1986). Identification of a putative progesterone receptor in the oviduct of a viviparous watersnake (Nerodia). Gen. Comp. Endocrinol., 61, 490-498.

Krohmer, R. W. (1986). Effects of mammalian gonadotropins (oFSH and oLH) on testicular development in the immature water snake, Nerodia sipedon. Gen. Comp. Endocrinol., 64, 330-338.

Krohmer, R. W. (2004). The male red-sided garter snake (Thamnophis sirtalis parietalis): reproductive pattern and behavior. ILAR J., 45, 54-74.

Krohmer, R. W., \& Crews, D. (1987a). Temperature activation of courtship behavior in the male red-sided garter snake (Thamnophis sirtalis parietalis): Role of the anterior hypothalamus-preoptic area. Behav. Neurosci., 101, 228-236.

Krohmer, R. W., \& Crews, D. (1987b). Facilitation of courtship behavior in the male red-sided garter snake (Thamnophis sirtalis parietalis) following lesions of the septum or nucleus sphericus. Physiol. Behav, 40, 759-765.

Krohmer, R. W., Bieganski, G. J., Baleckaitis, D. D., Harada, N., \& Balthazart, J. (2002). Distribution of aromatase immunoreactivity in the forebrain of red-sided garter snakes at the beginning of the winter dormancy. J. Chem. Neuroanat., 23, 59-71.

Krohmer, R. W., Grassman, M., \& Crews, D. (1987). Annual reproductive cycle in the male red-sided garter snake, Thamnophis sirtalis parietalis: Field and laboratory studies. Gen. Comp. Endocrinol., 68, 64-75.

LeMaster, M. P., \& Mason, R. T. (2002). Variation in a female sexual attractiveness pheromone controls male mate choice in garter snakes. J. Chem. Ecol., 28, 1269-1285.
LeMaster, M. P., \& Mason, R. T. (2003). Pheromonally mediated sexual isolation among denning populations of red-sided garter snakes, Thamnophis sirtalis parietalis. J. Chem. Ecol., 29, 1027-1043.

LeMaster, M. P., Moore, I. T., \& Mason, R. T. (2001). Conspecific trailing behaviour of red-sided garter snakes, Thamnophis sirtalis parietalis, in the natural environment. Anim. Behav., 61, 827-833.

Lerner, D. T., \& Mason, R. T. (2001). The influence of sex steroids on the sexual size dimorphism in the red-spotted garter snake, Thamnophis sirtalis concinnus. Gen. Comp. Endocrinol., 124, 218-225.

Licht, P. (1974). Reptilian endocrinology-the pituitary system. Chem. Zool., 9, 399-448.

Licht, P., \& Midgley, A. R. (1976). In vitro binding of radioiodinated human follicle-stimulating hormone to reptilian and avian gonads: Radioligand studies with mammalian hormones. Biol. Reprod., 15, 195-205.

Licht, P., \& Midgley, A. R. (1977). Autoradiographic localization of binding sites for human follicle-stimulating hormone in reptilian testes and ovaries. Biol. Reprod., 16, 117-121.

Licht, P., Farmer, S. W., Gallo, A. B., \& Papkoff, H. (1979). Pituitary gonadotropins in snakes. Gen. Comp. Endocrinol., 39, 34-52.

Licht, P., Miller, R., King, J. A., McCreery, B. R., Mendonça, M. T., Bona-Gallo, A., \& Lofts, B. (1984). Effects of chicken and mammalian gonadotropin-releasing hormone $(\mathrm{GnRH})$ on in vivo pituitary gonadotropin release in amphibians and reptiles. Gen. Comp. Endocrinol., 54, 89-96.

Licht, P., Papkoff, H., Farmer, S. W., Muller, C. H., Tsui, H. W., \& Crews, D. (1977). Evolution in gonadotropin structure and function. Rec. Prog. Horm. Res.., 33, 169-248.

Lofts, B., Phillips, J. G., \& Tam, W. H. (1966). Seasonal changes in the testes of the cobra, Naja naja (Linn). Gen. Comp. Endocrinol., 6, 466-475.

Lourdais, O., Bonnet, X., Shine, R., DeNardo, D., Naulleau, G., \& Guillon, M. (2002). Capital-breeding and reproductive effort in a variable environment: a longitudinal study of a viviparous snake. J. Anim. Ecol., 71, 470-479.

Lutterschmidt, D. I., \& Mason, R. T. (2005). A serotonin receptor antagonist, but not melatonin, modulates hormonal responses to capture stress in two populations of garter snakes (Thamnophis sirtalis parietalis and Thamnophis sirtalis concinnus). Gen. Comp. Endocrinol., 141, 259-270.

Lutterschmidt, D. I., \& Mason, R. T. (2008). Geographic variation in timekeeping systems among three populations of garter snakes (Thamnophis sirtalis) in a common garden. Physiol. Biochem. Zool., 81, 810-825.

Lutterschmidt, D. I., LeMaster, M. P., \& Mason, R. T. (2004). Effects of melatonin on the behavioral and hormonal responses of red-sided garter snakes (Thamnophis sirtalis parietalis) to exogenous corticosterone. Horm. Behav., 46, 692-702.

Madsen, T., \& Shine, R. (1994). Costs of reproduction influence the evolution of sexual size dimorphism in snakes. Evolution, 48, $1389-1397$.

Madsen, T., \& Shine, R. (1999). The adjustment of reproductive threshold to prey abundance in a capital breeder. J. Anim. Ecol., 68, 571-580.

Mason, R. T. (1993). Chemical ecology' of the red-sided garter snake, Thamnohhis sirtalis parietalis. Brain Behav. Evol.., 41, 261-268.

Mason, R. T., \& Crews, D. (1985). Female mimicry in garter snakes. Nature, 316, 59-60. 
Mason, R. T., Fales, H. M., Jones, T. H., Pannell, L. K., Chinn, J. W., \& Crews, D. (1989). Sex pheromones in snakes. Science, 245, 290-293.

Mathies, T., Felix, T. A., \& Lance, V. A. (2001). Effects of trapping and subsequent short-term confinement stress on plasma corticosterone in the brown treesnake (Boiga irregularis) on Guam. Gen. Comp. Endocrinol., 124, 106-114.

Mead, R. A., Eroschenko, V. P., \& Highfill, D. R. (1981). Effects of progesterone and estrogen on the histology of the oviduct of the garter snake, Thamnophis elegans. Gen. Comp. Endocrinol., 45, 345-354.

Mendonça, M. T., \& Crews, D. (1989). Effect of fall mating on ovarian development in the red-sided garter snake. Am. J. Physiol. Integr. Comp. Physiol., 257, 1548-1550.

Mendonça, M. T., \& Crews, D. (1990). Mating-induced ovarian recrudescence in the red-sided garter snake. I. Comp. Physiol., A, 166, 629-632.

Mendonça, M. T., \& Crews, D. (1996). Effects of ovariectomy and estrogen replacement on attractivity and receptivity in the red-sided garter snake (Thamnophis sirtalis parietalis). J. Comp. Physiol., A, 178, 373-381.

Mendonça, M. T., \& Crews, D. (2001). Control of attractivity and receptivity in female red-sided garter snakes. Horm. Behav, 40, $43-50$.

Mendonça, M. T., Daniels, D., Faro, C., \& Crews, D. (2003). Differential effects of courtship and mating on receptivity and brain metabolism in female red-sided garter snakes (Thamnophis sirtalis parietalis). Behav. Neurosci., 117, 144-149.

Mendonça, M. T., Tousignant, A. J., \& Crews, D. (1995). Seasonal changes and annual variability in daily plasma melatonin in the redsided garter snake (Thamnophis sirtalis parietalis). Gen. Comp. Endocrinol., 100, 226-237.

Mendonça, M. T., Tousignant, A. J., \& Crews, D. (1996a). Pinealectomy, melatonin, and courtship behavior in male red-sided garter snakes (Thamnophis sirtalis parietalis). J. Exp. Zool., 274, 63-74.

Mendonça, M. T., Tousignant, A. J., \& Crews, D. (1996b). Courting and noncourting male red-sided garter snakes, Thamnophis sirtalis parietalis: plasma melatonin levels and the effects of pinealectomy. Horm. Behav., 30, 176-185.

Moore, I. T., \& Jessop, T. S. (2003). Stress, reproduction, and adrenocortical modulation in amphibians and reptiles. Horm. Behav., 43, $39-47$.

Moore, M. C., \& Johnston, G. I. H. (2008). Toward a dynamic model of deposition and utilization of yolk steroids. Integr. Comp. Biol., 48, $411-418$

Moore, M. C., \& Lindzey, J. (1992). The physiological basis of sexual behaviour in male reptiles. In C. Gans, \& D. Crews (Eds.), "Biology of the Reptilia", Vol. 18 (pp. 70-113). Chicago, IL: University of Chicago Press.

Moore, I. T., Greene, M. J., \& Mason, R. T. (2001). Environmental and seasonal adaptations of the adrenocortical and gonadal responses to capture stress in two populations of the male garter snake, Thamnophis sirtalis. J. Exp. Zool., 289, 99-108.

Moore, I. T., LeMaster, M. P., \& Mason, R. T. (2000). Behavioural and hormonal responses to capture stress in the male red-sided garter snake, Thamnophis sirtalis parietalis. Anim. Behav, 59, $529-534$
Moore, I. T., Greene, M. J., Lerner, D. T., Asher, C. E., Krohmer, R. W., Hess, D. L., Whittier, J., \& Mason, R. T. (2005). Physiological evidence for reproductive suppression in the introduced population of brown tree snakes (Boiga irregularis) on Guam. Biol. Conserv., 121, 91-98.

Naulleau, G., \& Bonnet, X. (1996). Body condition threshold for breeding in a viviparous snake. Oecologia (Berlin), 107, 301-306.

Naulleau, G., \& Fleury, F. (1984). Relations entre la testosteronemie, la thyroxinemie et le cycle sexuel chez les males de Vipera aspis et Vipera berus. Bull. Soc. Herpetol. France, 32, 45-52.

Naulleau, G., \& Fleury, F. (1990). Changes in plasma progesterone in female Vipera aspis L. (Reptilia, viperidae) during the sexual cycle in pregnant and nonpregnant females. Gen. Comp. Endocrinol., 78, $433-443$

Naulleau, G., Fleury, F., \& Boissin, J. (1987). Annual cycle in plasma testosterone and thyroxine in the male aspic viper Vipera aspis $\mathbf{L}$. (Reptilia, Viperidae) in relation to the sexual cycle and hibernation. Gen. Comp. Endocrinol., 65, 254-263.

Nelson, R. J., Mason, R. T., Krohmer, R. W., \& Crews, D. (1987). Pinealectomy blocks vernal courtship behavior in red-sided garter snakes. Physiol. Behav., 39, 231-233.

Ng, T. B., Lee, H. M., Cheng, C. H. K., \& Wong, C. C. (1990). Partial purification of prolactin-like substance from snake (Ptyas mucosa) pituitaries. Endocrinologica Jap., 37, 777-786.

Ng, T. B., Lee, H. M., Cheng, C. H. K., \& Wong, C. C. (1993). Study of the purification of growth hormone-like substance from pituitaries of the snake Ptyas mucosa. Prep. Biochem., 23, 351-361.

Nozaki, M., Tsukahara, T., \& Kobayashi, H. (1984). Neuronal systems producing LHRH in vertebrates. In K. Ochiai (Ed.), "Endocrine Correlates of Reproduction" (pp. 3-27). New York: Verlag Press.

O'Donnell, R. P., Ford, N. B., Shine, R., \& Mason, R. T. (2004). Male redsided garter snakes, Thamnophis sirtalis parietalis, determine female mating status from pheromone trails. Anim. Behav., 68, 677-683

Osypka, N. M., \& Arnold, S. J. (2000). The developmental effect of sex ratio on a sexually dimorphic scale count in the garter snake Thamnophis elegans. J. Herpetol., 34, 1-5.

Ota, H., Hikida, T., Matsui, M., Mori, A., \& Wynn, A. H. (1991). Morphological variation, karyotype and reproduction of the parthenogenetic blind snake, Ramphotyphlops braminus, from the insular region of East Asia and Saipan. Amphibia-Reptilia., 12, 181-193.

Pang, S. F., Li, L., Ayre, E. A., Pang, C. S., Lee, P. P. N., Xu, R. K., Chow, P. H., Yu, Z. H., \& Shiu, S. Y. W. (1998). Neuroendocrinology of melatonin in reproduction: recent developments. J. Chem. Neuroanat., 14, 157-166.

Panzica, G. C., Viglietti-Panzica, C., \& Balthazart, J. (1996). The sexually dimorphic medial preoptic nucleus of quail: A key brain area mediating steroid action on male sexual behavior. Frontiers Neuroendocrinol., 17, 51-125.

Paolucci, M., Rocco, M., \& Varricchio, E. (2006). Leptin presence in plasma, liver and fat bodies in the lizard Podarcis sicula fluctuations throughout the reproductive cycle. Life Sci.., 69, 2399-2408.

Price, A. H., LaPointe, J. L., \& Atmar, J. W. (1993). The ecology and evolutionary implications of competition and parthenogenesis in Cnemidophorus. In J. W. Wright, \& L. J. Vitt (Eds.), "Biology of Whiptail Lizards. (Genus Cnemidophorus)” (pp. 371-410). Norman, OK: Oklahoma Museum of Natural History. 
Radder, R. S., \& Sline, R. (2007). Are the phenotypic traits of hatchling lizards affected by maternal allocation of steroid hormones to the egg? Gen. Comp. Endocrinol., 154, 111-119.

Reed, R. N. (2003). Interspecific patterns of species ricliness, geographic range size, and body size among New World venomous snakes. Ecography., 26, 107-117.

Riley, D., \& Callard, I. P. (1988). An estrogen receptor in the liver of the viviparous watersnake, Nerodia; characterization and seasonal changes in binding capacity. Endocrinology, 123, 753-761.

Riley, D., Kleis-San Francisco, S. M., \& Callard, I. P. (1988). A plasma steroid hormone binding protein in the viviparous water snake, Nerodia. Gen. Comp. Endocrinol., 71, 419-428.

Robert, K. A., Vleck, C., \& Bronikowski, A. M. (2009). The effects of maternal corticosterone levels on offspring behavior in fast- and slow-growth garter snakes (Thamnophis elegans). Horm. Behav., 55, 24-32.

Roselli, C. E., Horton, L. E., \& Resko, J. A. (1985). Distribution and regulation of aromatase activity in the rat hypothalamus and limbic system. Endocrinology, 117, 2471-2477.

Saint Girons, H. (1982). Reproductive cycles of male snakes and their relationships with climate and female reproductive cycles. Herpetologica, 38, 5-16.

Saint Girons, H., Bradshaw, D., \& Bradshaw, F. J. (1993). Sexual activity and plasma levels of sex steroids in the aspic viper Vipera aspis $\mathbf{L}$. (Reptilia, Viperidae). Gen. Comp. Endocrinol., 91, 287-297.

Schuett, G. W. (1996). Fighting dynamics of male copperheads, Agkistrodon contortrix (Serpentes, Viperidae): stress-induced inhibition of sexual behavior in losers. Zoo Biol.., 15, 209-221.

Schuett, G. W., \& Grober, M. S. (2000). Post-fight levels of plasma lactate and corticosterone in male copperheads, Agkistrodon contortrix (Serpentes, Viperidae): differences between winners and losers. Physiol. Behav, 71, 335-341.

Schuett, G. W., Harlow, H. J., Rose, J. D., Van Kirk, E. A., \& Murdoch, W. J. (1997a). Annual cycle of plasma testosterone in male copperheads, Agkistrodon contortrix (Serpentes, Viperidae): Relationship to timing of spermatogenesis, mating, and agonistic behavior. Gen. Comp. Endocrinol., 105, 417-424.

Schuett, G. W., Fernandez, P. J., Gergits, W. F., Casna, N. J., Chizar, D., Smith, H. M., et al. (1997b). Production of offspring in the absence of males: evidence for facultative parthenogenesis in bisexual snakes. Herpetol. Nat. Hist., 5, 1-10.

Schuett, G. W., Repp, R. A., Taylor, E. N., DeNardo, D. F., Early, R. L., Van Kirk, E. A., \& Murdoch, W. J. (2006). Winter profile of plasma sex steroid levels in free-living male western diamond-backed rattlesnakes, Crotalus atrox (Serpentes: Viperidae). Gen. Comp. Endocrinol., 149, 72-80.

Schuett, G. W., Carlisle, S. L., Holycross, A. T., O'Leile, J. K., Hardy, D. L., Sr., Van Kirk, E. A., \& Murdoch, W. J. (2002). Mating system of male Mojave rattlesnakes (Crotalus scutulatus): seasonal timing of mating, agonistic behavior, spermatogenesis, sexual segment of the kidney, and plasma sex steroids. In G. W. Schuett, M. Hoggren, M. E. Douglas, \& H. W. Greene (Eds.), "Biology of the Vipers" (pp. 515-532). Eagle Mountain, Utah: Eagle Mountain Publishing.

Schuett, G. W., Hardy, D. L., Sr., Greene, H. W., Earley, R. L., Grober, M. S., Van Kirk, E. A., \& Murdoch, W. J. (2005). Sympatric rattlesnakes with contrasting mating systems show differences in seasonal patterns of plasma sex steroids. Anim. Behav., 70, 257-266.
Schwabl, H. (1993). Yolk is a source of maternal testosterone for developing birds. Proc. Natl. Acad. Sci. U.S.A., 90, 11446-11450.

Sherwood, N. M., \& Whittier, J. M. (1988). Gonadotropin-releasing hormone from brains of reptiles: turtles (Pseudemys scripta) and snakes (Thamnophis sirtalis parietalis). Gen. Comp. Endocrinol., 69, 319-327.

Shine, R. (1985). The evolution of viviparity in reptiles: an ecological analysis. In C. Gans, \& F. Billet (Eds.), "Biology of the Reptilia, Vol. 15" (pp. 605-694). New York: John Wiley and Sons.

Shine, R. (2003). Reproductive strategies in snakes. Proc. R. Soc. Lond. B., 270, 995-1004.

Shine, R., Harlow, P., LeMaster, M. P., Moore, I. T., \& Mason, R. T. (2000c). The transvestite serpent: why do male garter snakes court (some) other males? Anim. Behav., 59, 349-359.

Shine, R., O'Connor, D., \& Mason, R. T. (2000a). The problem with courting a cylindrical object: how does an amorous male snake determine which end is which? Behaviour, 137, 727-739.

Shine, R., Olsson, M. M., \& Mason, R. T. (2000b). Chastity belts in gartersnakes: the functional significance of mating plugs. Biol. J. Linn. Soc., 70, 377-390.

Shine, R., Phillips, B., Waye, H., LeMaster, M., \& Mason, R. T. (2004). Species-isolating mechanisms in a mating system with male mate choice (garter snakes, Thamnophis spp). Can. J. Zool., 82, 1091-1098.

Shine, R., Reed, R. N., Shetty, S., LeMaster, M., \& Mason, R. T. (2002). Reproductive isolating mechanisms between two sympatric sibling species of sea snakes. Evolution. 56, 1655-1662.

Silveira, P. F., Schiripa, L. N., Carmona, E., \& Picarelli, Z. P. (1992). Circulating vasotocin in the snake Bothrops jararaca. Comp. Biochem. Physiol., 103A, 59-64.

Smith, M. T., Moore, F. L., \& Mason, R. T. (1997). Neuroanatomical distribution of chicken-I gonadotropin-releasing hormone (cGnRH-I) in the brain of the male red-sided garter snake. Brain Behav. Evol.., $49,137-148$.

Stevens, G. C. (1989). The latitudinal gradient in geographical range: how so many species coexist in the tropics. Am. Nat., 133, 240-256.

Tamarkin, L., Baird, C. J., \& Almeida, O. F. (1985). Melatonin: a coordinating signal for mammalian reproduction? Science, 227(4688), $714-720$.

Taylor, E. N., \& DeNardo, D. F. (2005). Reproductive ecology of Western Diamond-backed Rattlesnakes (Crotalus atrox) in the Sonoran Desert. Copeia, 2005, 152-158.

Taylor, E. N., DeNardo, D. F., \& Jennings, D. H. (2004). Seasonal steroid hormone levels and their relation to reproduction in the Western Diamond-backed rattlesnake, Crotalus atrox (Serpentes: Viperidae). Gen. Comp. Endocrinol., 136, 328-337.

Thapliyial, J. P., Kumar, D. S., \& Oommen, O. V. (1975). Variations in thyroid activity and respiratory rate during a 24 -hr period and role of testosterone and thyroxine on the oxidative metabolism of the water snake, Natrix piscator. Gen. Comp. Endocrinol., 26, 100-106.

Tilden, A. R., \& Hutchison, V. H. (1993). Influence of photoperiod and temperature on serum melatonin in the diamondback water snake, Nerodia rhombifera. Gen. Comp. Endocrinol., 92, 347-354.

Tosini, G. (1997). The pineal complex of reptiles: physiological and behavioral roles. Eth. Ecol. Evol., 9, 313-333.

Tsai, T., \& Tu, M. (2001). Reproductive cycle of female Chinese green tree vipers, Trimeresurus stejnegeri stejnegeri, in northern Taiwan. Herpetologica, 57, 157-168. 
Tsui, H. W., \& Licht, P. (1977). Gonadotropin regulation of in vitro androgen production by reptilian testes. Gen. Comp. Endocrinol., 31, 422-434

Tsutsui, K., Saigoh, E., Ukena, K., Teranishi, H., Fujisawa, Y., Kikuchi, M., Ishii, S., \& Sharp, P. J. (2000). A novel avian hypothalamic peptide inhibiting gonadotropin release. Biochem. Biophys. Res. Commun., 275, 661-667.

Turner, J. E., \& Tipton, S. R. (1972a). Environmental temperature and thyroid function in the green water snake, Natrix cyclopion. Gen. Comp. Endocrinol., 18, 195-197.

Turner, J. E., \& Tipton, S. R. (1972b). Metabolic response to temperature acclimation and $\mathrm{T}_{4}$ in the water snake. Gen. Comp. Endocrinol., 18, 98-101.

Ubuka, T., McGuire, N. L., Calisi, R. M., Perfito, N., \& Bentley, G. E. (2008). The control of reproductive physiology and behavior by gonadotropin-inhibitory hormone. Integr. Comp. Biol., 48, $560-569$.

Uller, T., \& Olsson, M. (2008). Multiple paternity in reptiles: patterns and processes. Mol. Ecol., 17, 2566-2580.

Uribe, M. C., González-Porter, G., Palmer, B. D., \& Guillette, L. J., Jr. (1998). Cyclic histological changes of the oviductal-cloacal junction in the viviparous snake Toluca lineata. J. Morphol., 237, 91-100.

Vagell, M. E., \& McGinnis, M. Y. (1997). The role of aromatization in the restoration of male rat reproductive behavior. J. Neuroendocrinol., 9 , 415-421.

Vitt, L. J. (1992). Diversity of reproductive strategies among Brazilian lizards and snakes: The significance of lineage and adaptation. In W. C. Hamlett (Ed.), "Reproductive Biology of South American Vertebrates" (pp. 135-149). New York: SpringerVerlag.
Weil, M. R. (1982). Seasonal effects of mammalian gonadotropins (bFSH and bLH) on plasma androgen levels in male water snakes, Nerodia sipedon. Comp. Biochem. Physiol. A: Physiol., 73, 73-76.

Weil, M. R., \& Aldridge, R. D. (1981). Seasonal androgenesis in the male water snake Nerodia sipedon. Gen. Comp. Endocrinol., 44, 44-53.

Whittier, J. M. (1992). Effects of sex steroid implants on reproductive tissues of female garter snakes (Thamnophis sirtalis). J. Morphol., $214,43-48$.

Whittier, J. M., \& Crews, D. (1987). Seasonal reproduction: Patterns and control. In D. O. Norris, \& R. E. Jones (Eds.), "Hormones and Reproduction in Fishes, Amphibians, and Reptiles" (pp. 385-409). New York: Plenum.

Whittier, J. M., \& Crews, D. (1989). Mating increases plasma levels of prostaglandin F2 alpha in female garter snakes. Prostaglandins, 37, 359-366.

Whittier, J. M., Mason, R. T., \& Crews, D. (1987a). Plasma steroid hormone levels of female red-sided garter snakes Thamnophis sirtalis parietalis: Relationship to mating and gestation. Gen. Comp. Endocrinol, 67, 33-43.

Whittier, J. M., Mason, R. T., Crews, D., \& Licht, P. (1987b). Role of light and temperature in the regulation of reproduction in the red-sided garter snake, Thamnophis sirtalis parietalis. Can. J. Zool., 65, 2090-2096.

Wingfield, J. C., Maney, D. L., Breuner, C. W., Jacobs, J. D., Lynn, S., Ramenofsky, M., \& Richardson, R. D. (1998). Ecological bases of hormone-behavior interactions: the "emergency life history stage.". Am. Zool, 38, 191-206.

Zaidan, F., III, Kreider, D. L., \& Beaupre, S. J. (2003). Testosterone cycles and reproductive energetic: Implications for northern range limits of the cottonmouth (Agkistrodon piscivorus leucostoma. Copeia, 2003, 231-240. 